\title{
Study on the Intellectual Property Management in Colleges and Universities at New Stage
}

\author{
Wan $\mathrm{Li}^{1, \mathrm{a}, *}$ and Wang Yinhong ${ }^{1, \mathrm{~b}, *}$ \\ ${ }^{1}$ Discipline Construction Office, China University of Geosciences, Beijing, China \\ ${ }^{\mathrm{a}}$ wanli@cugb.edu.cn, ${ }^{\mathrm{w}} \mathrm{wyh@cugb.edu.cn}$ \\ *corresponding authors
}

Keywords: Colleges and Universities, Intellectual Property Management, Double-Class Construction

\begin{abstract}
At present, colleges and universities have been regarded as an important force for the knowledge creation and high-tech innovation, so they should pay full attention to the intellectual property management in the research process of the science and technology project. In order to strengthen the intellectual property management and improve the management level of the intellectual property rights in colleges and universities, especially higher universities of geosciences, authors analyze the main existing problems in intellectual property management, including the lacking the protection consciousness of intellectual property rights, the imbalance between the quantity of intellectual property application and transformation, and the imperfection of incentive mechanism. Hence, we suggest that the administrative staff should improve the protection consciousness of the intellectual property rights, develop the relevant intellectual property regulations, strengthen the construction of the intellectual property management institutions, and further perfect the rewarding mechanism of the intellectual property rights in higher universities of geosciences at new stage.
\end{abstract}

\section{Introduction}

Under the new situation of the double-class construction, the intellectual property rights will play an increasingly important role in China's scientific and technological innovation and economic development. At the same time, the intellectual property rights have become an important part of the science and technology management in colleges and universities, and the quality and quantity of intellectual property rights have been regarded as one of the important symbols to assess the science and technology level and the innovation ability of colleges and universities. Therefore, improving the ability and management level of the intellectual property protection are very beneficial to strengthen the independent innovation ability in colleges and universities, and even to promote the development of the science and technology and economy in China. However, how to scientifically manage the intellectual property rights, avoid the loss of intellectual property rights, and improve the quantity of patent application, authorization, and transformation, are becoming one of the key problems for the department of science and technology in colleges and universities.

\section{Main Contents Of The Intellectual Property Management In Colleges And Universities}

In the colleges and universities, the main contents of the intellectual property management include the patent rights, the trademark rights, the commercial and technical secrets, the college's rights of name tag and relative rights and copyrights, and other intellectual property rights in accordance to the laws, rules and regulations. For colleges and universities, the patent rights refer to that the university scientific researchers obtain a kind of exclusive rights invention in accordance with the patent law, and the patent management is one of the most important contents in the management of intellectual property rights [1]. 
In order to strengthen the management of intellectual property rights in colleges and universities, it is very necessary to establish an effective intellectual property management system, standardize the procedures of intellectual property management, so as to fully stimulate the enthusiasm of researchers and teachers of the science and technology, to produce more independent innovation of intellectual property rights of the core competitiveness, and to cultivate the favorable environment for the intellectual property protection and the reasonable operation mechanism and mature management system in the colleges and universities [2].

\section{Existing Problems In The Intellectual Property Management And Protection In Colleges And Universities}

In recent years, development of the intellectual property management system has made great progress in colleges and universities. It is also well recognized that this work plays an important role in promoting effective technological development of colleges and universities and serving local economic construction. However, owing to the influence of various factors including economy and technology, there are still many problems in the intellectual property management, and the intellectual property management system is still imperfect in our colleges and universities [3].

Therefore, combined with the reality, especially double-class construction, to explore the intellectual property protection and management of colleges and universities, it is very significant to promote the development of the science and technology and to adapt to the implementation of the state intellectual property strategy.

A. The management model of intellectual property protection is imperfect

Owning to implement the scientific research project management mode for a long time in colleges and universities, the consciousness of the intellectual property protection and economic knowledge of these scientific research administrative staff are still not enough [3, 4]. In the process of the scientific research project application, implementation and latter transformation of the scientific and technological achievements, a majority of scientific research administrative staff or scientific research personnel with barely law knowledge of the intellectual property protection, put more attention to technological achievements' identification, publishing papers and applying for science and technology awards than to effectively protecting scientific and technological achievements by the form of the intellectual property protection laws.

During the project application, applicants may focus on how to make application done well for project funding, ignore how to make the innovative design or previous scientific research achievements projected by applying patents, so that those achievements would be public in the course of project application, which eventually led to the losses of the intellectual property [4].

Additionally, in the transformation and promotion of the scientific and technological achievements, the scientific researchers only pay attention to whether the achievements could transform successfully, but they don't completely pay attention to whether they could apply for patents, so as to make those achievements public and led to the losses of the intellectual property in colleges and universities.

\section{B. The imbalance among the quantity of patent application, authorization and transformation}

The intellectual property management is an important part of the science and technology management in colleges and universities. However, the patents are one of the most important output forms of the intellectual property, and the quantity of patent application, authorization and transformation has become one of the key symbols to evaluate the scientific and technological level in colleges and universities.

For the current situation, the quantity of patent application in colleges and universities is still not enough. In addition, the quantity of patent application, authorization and transformation in colleges and universities is severely imbalanced. For China University of Geosciences in Beijing (CUGB), the patent 
data reveal that the transformation rate of patents was less than $2 \%$ in recent years. The authorization and transformation rates are lower than that of the national average level, and this will cause some original achievements to fail to transform, eventually leading to the waste of the intellectual property achievements.

\section{Lacking the management talents of the intellectual property rights}

At present, several colleges and universities still don't arrange for the inter-disciplinary talents to take charge of the administration of intellectual property rights. Even if some universities have arranged the full-time staff, they don't have much normal and systemic education about the intellectual property management, and only few have obtained the patent agent qualification [4, 5] In addition, the administrators of science and technology management pay more attention to administrations, and not only have little knowledge of teachers' scientific and technological achievements, but also have insufficient understanding of the technology needed by enterprises. Therefore, the excellent scientific research cannot be promoted in time, and research funds are difficult to introduce in colleges and universities.

Most scientific and technological achievements with market prospects have to remain at the theoretical and experimental level. It is also difficult to quickly convert mature technology into something that will suit the demands of both the enterprise and the market due to the wall between research and supply and demand potential, thus hindering the leap from the experimental stage to the productivity. Due to the lack of the specialized talents to manage the intellectual property rights, there exist the phenomenon of technological achievements losses for several universities in science and technology activities, and this will have an effect on the earnings of technology ownership in colleges and universities [5].

\section{Lacking corresponding funds and effective incentive mechanisms}

At present, our country has issued new laws and regulations such as patent law, suggesting that the researchers who apply for patents should be supported by certain research funds, and the researchers who achieve the intellectual property rights should be rewarded with a certain amount of money.

Due to the lack of the scientific research funds, several colleges and universities do not implement the incentive mechanism. Even though some colleges and universities implement the incentive mechanism, the material incentives in these universities are distinctly lower than those of the developed countries [4, 6]. Consequently, teachers and researchers hardly afford the patent application cost and the patent maintaining cost without enough research funds, so that they have to abandon the rights of patent application or early suspend patent rights. What's more, the proportion of patent application, authorization and transformation is very small in the evaluation process of scientific research level. As a result, many teachers and researchers generally tend to publish papers rather than to apply for patents.

\section{Discussing On The Countermeasures Of Promoting The Intellectual Property Protection And Management In Colleges And Universities}

4.1 Improve the protection consciousness of the intellectual property rights and perfect relevant regulations of the intellectual property rights in colleges and universities

The researchers and administrators of colleges and universities should improve the protection consciousness of the intellectual property rights, especially their economic and institutional cognizance, and should take it as a long-term work of science and technology management. The lack of intellectual property protection consciousness will result in the intellectual property loss in colleges and universities [7]. Therefore, the science and technology departments in colleges and universities should strengthen the talent cultivation of the intellectual property management, gradually improve the protection consciousness of the intellectual property rights of the teachers and researchers, and make them fully 
realize the importance of the intellectual property protection.

The science and technology departments in colleges and universities should invite periodically experts to have lectures and special reports on intellectual property rights so as to make teachers and researchers further understand and grasp the contents of the intellectual property rights and related policies and regulations, to learn how to apply, maintain and implement the patents, and even to know how to use the intellectual property rights to protect its own technological achievements.

At present, the phenomenon of intellectual property loss in colleges and universities still exists, thus colleges and universities should further strengthen the system construction of the intellectual property protection, and perfect the regulations of the intellectual property management $[6,7]$. In order to do well in the work of the intellectual property rights in colleges and universities, it is necessary to establish an innovative intellectual property protection system, and the intellectual property work should be done in the following aspects:

1) Formulate the regulations related to intellectual property rights in combination with their own situation, clarify the protection procedures of the intellectual property rights, and promote the development of intellectual property protection system in a systematic and scientific direction.

2) Clarify the ownership of intellectual property rights, protect the legal rights of patent inventors, and truly inspire the innovation and enthusiasm of teachers and researchers in the scientific research.

3) Strengthen the enforcement of intellectual property protection, strict the technical contract review system, and avoid the loss of the intellectual property in colleges and universities.

4) Perfect the intellectual property protection and management regulations, set up the intellectual property management funds, establish the incentive mechanism for promoting scientific and technological innovation, and focus on the industrialization of intellectual property achievements.

\subsection{Strengthen the construction of the specialized intellectual property management institutions}

Colleges and universities should perfect the institutional construction of scientific and technological achievements, and they should improve security systems for implementation acts to strengthen intermediaries' service and construction of network-based information platforms. This is helpful in promoting a smooth flow of knowledge and effective transfer of technology between developers and markets, and in providing effective technical consulting services for the implementation of scientific and technological achievements [7,8]. All of these can greatly improve the success rate of the transformation of the intellectual property rights.

1) Set up an independent intellectual property management agency.

Colleges and universities should set up an independent intellectual property management agency, provide necessary equipment and funds, and arrange the specific intellectual property management team so as to effectively complete the intellectual property management work during the project implementation process.

Additionally, colleges and universities should also develop enforceable measures to manage the intellectual property rights with an emphasis on patent protection and contract management, and make the protection work of the science and technology innovation achievements into effect. In this way, it is not only beneficial to promote the scientific management of the intellectual property rights in science and technology projects, but also to protect the intellectual property rights in colleges and universities.

2) Establish the intellectual property information management system.

First, the establishment of the intellectual property information management system will be helpful to share with the scientific research management system associated with technology information, and helpful to combine the intellectual property management with the project management of science and technology in colleges and universities $[7,8]$.

Second, higher universities and enterprises should further promote cooperation with the public 
information platform construction of the intellectual property rights, so that the researchers can fully grasp the existing patents and other intellectual property rights, and these will stimulate them to create more intellectual achievements.

Whether or not information can flow well between universities and businesses will certainly have an impact on the success transformation of intellectual property rights in colleges and universities [7, 9]. If there is a lack of information exchange between universities and businesses, colleges and universities will not fully understand enterprises, and can't create scientific and technological achievements that adapt to the demands of enterprise.

3) Create the technological transfer office for intellectual property rights.

The real value of the technological achievements as assets in colleges and universities can be reflected and obtained by the legal operation. Therefore, the technological transformation for intellectual property rights to economic benefits becomes an important work to the management department of intellectual property rights in colleges and universities.

Looking at successful cases in American colleges, the standard model of technological transfer involves establishing a technological transfer office which consists of legal, business and specialized technological personnel[9, 10,11]. The main work includes patent marketing, providing intermediary service, reasonable distribution and operation according to law, and establishing the necessary system to support implementation. Referring to the successful experience of the United States, setting up an intellectual property transfer office in our universities, the transformation level of technological achievements will reach new heights.

4.3 Enlarge the investment on intellectual property rights and cultivate professional administrative talents of the intellectual property rights

The government should attach great importance to the construction of the intellectual property rights, and further provide the equipment and funding for the innovation ability construction of the intellectual property rights so as to avoid the loss of the intellectual property rights in colleges and universities. In addition, along with the intense technological competition, colleges and universities also should actively seek various channels of funds to make sufficient material guarantee for their own scientific and technological innovations, and they also should set up special intellectual property protection fund for the patent application, patent maintenance, and intellectual property training, so as to further improve the output ability and level of intellectual property rights $[10,11]$.

The intellectual property management of colleges and universities involves various professional fields, so it is necessary for intellectual property personnel to understand both laws and natural science. Therefore, colleges and universities should attach great importance to knowledge, talent and education in the future, improve the comprehensive abilities of the intellectual property personnel, and cultivate excellent interdisciplinary talents. On the one hand, colleges and universities should attach importance to the administrative talents of the intellectual property rights, and provide a good environment and preferential treatment for them. On the other hand, they should enlarge the investment on the training and education of these administrative talents, and support them to take part in the academic communication of intellectual property rights at home and abroad [12,13]. In a word, colleges and universities should accelerate construction of the professional administrative talents, so as to further promote the technological transformation for intellectual property rights.

\subsection{Perfect the rewarding mechanism of intellectual property management}

In the intellectual property management of colleges and universities, the scientific and reasonable intellectual property management incentive and reward system is the important factor to stimulate the innovation enthusiasm of teachers and researchers. Colleges and universities should formulate the corresponding incentive system to standardize and institutionalize the intellectual property management, 
so that intellectual property rights can stimulate and guarantee the innovation of science and technology.

Combined with the intellectual property rights incentive method in CUGB [8,9], we present the following suggestions:

Firstly, colleges and universities should safeguard the lawful rights and interests of teachers and researchers possessing the invention, creation and technological achievements, and should reward the teachers and researchers who make considerable contribution to creation, development, and transformation of the intellectual property rights in accordance with the relevant regulations.

Second, colleges and universities should encourage the transformation of technological achievements. If the new technological achievements are transferred successfully, the teachers and researchers possessing the achievements may be entitled to no less than $30 \%$ of the income, and the leading responsible person shall be reward no less than $50 \%$ of the total bonus.

Third, colleges and universities should encourage should take the intellectual property rights as a factor in the evaluation of the professional title and the post salary.

Fourth, colleges and universities should set up the separated fund for applying patents, and the funds shall be provided for use with compensation in accordance with relevant regulations, so as to encourage patent applications.

\section{Conclusions}

In brief, numerous high-tech achievements are from the colleges and universities. It is entirely necessary for colleges and universities, especially higher universities of geosciences, to take countermeasures to strengthen the intellectual property management and improve the management level of the intellectual property rights. However, there still exist some problems in the intellectual property management, including the lacking the protection consciousness of intellectual property rights, the imbalance between the quantity of intellectual property application and transformation, and the imperfection of incentive mechanism. Based on these existing disadvantages, the authors suggest that main administrative staff should improve the protection consciousness of the intellectual property rights, develop the relevant intellectual property regulations, conduct the construction of the intellectual property management institutions, and further perfect the rewarding mechanism of the intellectual property rights in higher colleges and universities.

\section{References}

[1] X.Z. Yuan, "The unbalanced development of intellectual property rights and countermeasures in colleges and universities", Journal of Civil Aviation Flight University of China,vol.17, pp:61-64, 2006.

[2] X.G. Zhu and D.S. Tang, "Brief discussion on the intellectual property management model in colleges and universities", Jiangsu Higher Education, no.5, pp,51-53, 2004.

[3] N. Han and Y.L Li, "Brief analysis on perfecting intellectual property management system in colleges and universities", Intellectual Property, no.3, pp.52-55, 2011.

[4] Z.J Tang, "Problems and countermeasures in the intellectual property management in colleges and universities", Legal System and Society, no.6, pp.182-183, 2018.

[5] G.J. Shen, "The necessity of establishing intellectual property management institution in higher universities", Journal of Technology College Education,vol.25, pp.91:92, 2006.

[6] J. Peng, "Analysis on the management and protection of intellectual property in polleges and pniversities", China Invention and Patent, vol.15, pp.94-97, 2018.

[7] Z.G Wang and T. Ling, "Brief analysis on the status of intellectual property management in colleges and universities and related countermeasures", Science and Technology Management Research, vol.9, pp.143-146, 2008. 
[8] Y.H. Wang, "Discussion on reform and innovation of scientific and technological management in higher universities at new stage", Chinese Geological Education, vol.16, no.1, pp. 98-101, 2007.

[9] Y.H. Wang, L. Wan, X.H. Lei, "Countermeasures and suggestions for improving management of science and technology achievements in higher universities of geosciences at new stage", International Conference on Economic and Information management, pp.67-70, 2011.

[10] Y.H. Wang, L. Wan, R.S. Ji, "Statistical analysis of SCI papers published by China University of Geosciences(Beijing)", Bulletin of National Natural Science Foundation of China, no.2, pp.153-156, 2014.

[11] D. Zhang, "Study on the university intellectual property on process management of science and technology program", Scientific Management Research, vol.28, pp.49-51, 2010.

[12] Y.H. Jin and L.Q. Mao, "The experience of intellectual property rights management and the enlightenment in American universities", Electronics Intellectual Property, no. 2, pp.36-38, 2007.

[13] X. Han, "Study on the standardization of intellectual property management for high education institutions", Journal of Nanjing University of Science and Technology( Social Science Edition), vol.29, pp.40-44, 2016. 